Patel, V.V., Karia, N., Pandit, D. (2018). "Identifying value enhancing factors and applicability of visual management tools" In: Proc. $26^{\text {th }}$ Annual Conference of the International. Group for Lean Construction (IGLC), González, V.A. (ed.), Chennai, India, pp. 282-293. DOI: https://doi.org/10.24928/2018/0239. Available at: www.iglc.net.

\title{
IDENTIFYING VALUE ENHANCING FACTORS AND APPLICABILITY OF VISUAL MANAGEMENT TOOLS
}

\author{
Vyoma Vipul Patel ${ }^{1}$, Nimitt Karia², and Devanshu Pandit ${ }^{3}$
}

\begin{abstract}
A significant amount of capital has been invested in AECO industry for many decades to support public and private initiatives. Therefore, getting reasonable value from the investment is pivotal for any developing nation. Interpretation of the value varies according to the importance and influence of the stakeholders in the project hence knowing its perception is significant. Maximising value is one of the foundations of the lean construction approaches. On the other hand, as Indian construction industry is gearing up for lean construction and its applications, understanding the meaning of the value in local context become significant. Moreover, visual management and its applications in construction have shown promising results. Therefore, how well they can address value maximization in Indian construction context is answered via conducted research.

This paper helps to understand the perception of the value in the Indian construction industry through semi-structured interviews of construction professionals. Additionally, value increasing factors are identified in the construction phase of the project, subsequently; lean visual tools are applied to identify factors. The results demonstrate that the visual management tools have potential to increase value in the construction phase of Indian construction projects.
\end{abstract}

\section{KEYWORDS}

Value, Visual Tools, Construction phase, Factors, Indian construction projects

\section{INTRODUCTION}

As defined by Koskela et al (2002), lean construction is the approach to design production system which has minimum wastage to obtain the best value. Therefore, maximizing the value is one of the major philosophy for the lean construction point of

1 Undergraduate student, Faculty of Technology, CEPT University, Ahmedabad, India, +91 99785 01302, vyoma.v.patel@gmail.com

2 Managing Partner, development2020 and visiting professor, CEPT University, Ahmedabad, India, +91 98797 99213, nimittkaria@gmail.com

3 Professor, Faculty of Technology, CEPT University, Ahmedabad, +91 7698987575, devanshu@cept.ac.in 
view. Furthermore, the term value can be defined as the relationship between function, time, cost and quality (Kelly, Male, \& Graham, 2004). But, stakeholders from construction projects define the value of the project based on their expectations from the project (Kelly et al., 2009). However, according to Kashiwagi and Savicky (2003), understanding about concept of value among construction projects is lacking.

Therefore, to maximize or increase the value of the construction project it is necessary to understand the perception of the construction clients, internal and external both. Moreover, organizations from Indian construction industry are taking steps forward for lean construction (Anerao, 2016). Thus, this research is carried out with objective to understand the perception of value in Indian construction industry. The study further identifies factors affecting the value of project through qualitative and quantitative approaches.

To enhance communication and to control operations and processes in real time, the visual management and its tool have been developed and used by lean practitioners (Parry $\&$ Turner, 2006). Moreover, the successful application of visual management in construction has been proven in the transportation sector, building sector and industrial sectors (Tezel \& Aziz, 2017; Tezel et al, 2013, Tezel et al, 2016). The applicability of the visual management tools in Indian construction sector is explored in this research paper using relation matrix. In particular, the matrix shows the relationship between visual management tools and value improvement factors in terms of applicability and ease of implementation.

\section{RESEARCH METHOD}

Following the 'research onion' provided by Saunders et al. (2007), this research is classified into various layers which describe research methodology. Consequently, the research falls under 'epistemology' (pragmatism) as research philosophy along with deductive approach and survey strategy is adopted. According to Spector et al. (2014), descriptive research answers "what is" type of research questions. This type of design requires both qualitative and quantitative approaches (AECT, 2018). Therefore, the qualitative research tools such as personal interviews and opinion survey are considered along with quantitative tools such as factor analysis, and matrix rating.The overall research methodology adopted for the study is illustrated in Figure 2.

\section{DATA COLLECTION}

Clear definition of the universe, population, unit of analysis, sample frame, sample sizes are essential for determining successful data collection approach design (Tobergte \& Curtis, 2013). As this research comprises of three objectives, the data collection method varies accordingly.

\section{VALUE PERCEPTION OF INDIAN CONSTRUCTION INDUSTRY}

To determine the perception of value in Indian construction industry, semi-structured interviews were carried out as shown in Figure 2. 10 industry professionals working in different positions including designer, value engineer, project manager, construction

manager, client, consultants, and civil engineers were selected. Interviews were 
conducted to determine value in the construction phase, value influencing parameters, value improving parameters, improvement priorities, and finally to come with recommendations.

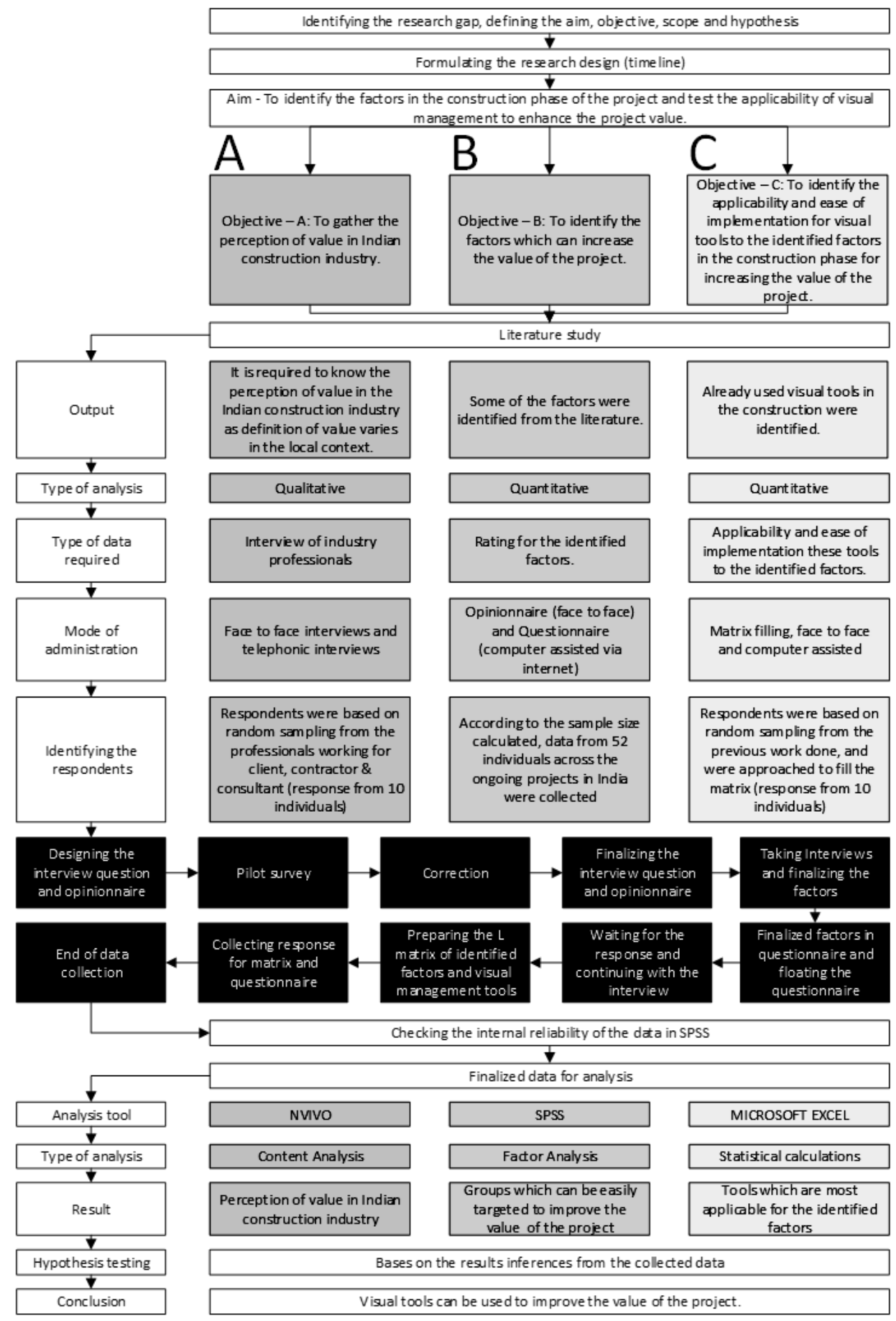

Figure 1: Research Method 


\section{DETERMINING FACTORS}

Literature study and opinionnaire from industry experts resulted identification of 33 factors that can improve the value of a construction project. A questionnairewas formed comprising of all 33 factors to obtain the response ratings against each factor. Likert scale was used for the importance ranking. On the basis of sample size calculation suggested by Morgan and Krejcie (1970), 52 samples were required. Data collection from 52 individuals across India was received. Additionally, information regarding respondent is captured as - categories of the projects, company's annual turnover, cost of a current project, respondent's experience in construction industry, education qualification, payment mechanism, designation, type of procurement in the current project, type of organization.

\section{'FACTOR VS. VISUAL MANAGEMENT TOOLS' MATRIX}

Based on the visual management tools listed by Tezel (2013) and Tezel et al (2011); commonly used visual management tools were plotted on L shaped matrix against identified factors in the constructionphase of a project. This matrix was circulated to the lean experts for determining the relationship between factors and tools based on their applicability and feasibility in Indian construction industry as stated through research methodology in Figure 2.Respondents to this include lean practitioners, professors, directors, lean advisors and managing partners having $20+$ years of experience.

\section{DATA ANALYSIS}

A different set of methods are utilized to analyzethe collected data. Summary of data analysis can be inferred from Figure 2.

\section{CONTENT ANALYSIS FOR VALUE PERCEPTION OF INDIAN CONSTRUCTION INDUSTRY}

The interview scripts are transcribed and further processed in NVIVO qualitative analysis tool. Several nodes and codes are created to carryout content analysis of collected data. Word frequency, text queries and code analysis were performed to interpret collected data describing them under type of analysis in Figure 2.

\section{FACTOR ANALYSIS OF DETERMINED FACTORS AND THEIR RELIABILITY}

According to (Trochim and Donnelly, 2006), reliability was used to check the appropriateness of the collected data in SPSS software. The value obtained from the testwas 0.931 (Cronbach's Alpha), 0.855 (Spearman-Brown Coefficient), 0.847 (Guttman Split-Half Coefficient). This result reveals that the collected data is reliable. Further, as said by Johnson and LeBreton (2004) and (Norusis, 1992), Factor analysis(Figure 2) is performed to recognizea small set of groups which can represent the relationships within the set of interrelated variables.Also, some additional test comprising Bartlett test of Sphericity (Approx. Chi-Square $=1129.66)$, associated significance level $(0.000)$, KaiserMeyer-Olkin measure of sampling adequacy value $(0.713)$ has been performed where all results were found satisfactory. The results of totalvarianceis tabulated in Table 1and rotated matrix is tabulated in Table 2 . 


\section{ANALYSING FOR 'FACTOR VS. VISUAL MANAGEMENT TOOLS' MATRIX}

As shown in the Table 3 and 4, the relational matrixes have been prepared from the expert opinion and ratings. Simply, based on the scores they have achieved, the inferences for most addressed factor and the most useful tool is stated in the result section. Conditional formatting and data filtration methods were used to infer the collected data.

\section{RESULT DISCUSSION AND INFERENCES}

\section{PERCEPTION OF VALUE IN THE INDIAN CONSTRUCTION INDUSTRY}

Value is a very subjective term depending on the perspective of the stakeholders. It is believed that if something more is received for the price paid than that is value. In the construction industry; quality, cost, benefits, etc. are considered the value. In the construction phase, it could be valuedin terms of saving time, reducing misuse of resources - manpower, material and of course value engineering addition for suggesting a specific system which is not going to reduce your quality but it's going to be beneficial either in time or cost. Yes, time and cost are given the utmost importance in our Indian construction industry.

If efforts are made in the correct direction during the construction phase of the project, the value of the project can be increased. With the current practices and different mindsets, individuals are not satisfied with the construction industry. They emphasize for improvement in areas likeproject management, current working systems, quality improvement, detailed planning in the design phase, etc. And a strong belief is shown saying that client is responsible for the smooth completion of the projects. After client comes to the consultants, they play a role by helping the client in taking contractual decisions, convincing the stakeholders for the benefit of the project and a constant observation of consistent performance by the parties involved in the project. Then comes a contractor, who can perform best in parameters like cost, time, quality, satisfaction, function, aesthetics, design, services, money, overall performance, etc. during the construction phase. During this period focus should be on the process and the product, as they are equally important. Most of the respondents agree on that, improving the process automatically improves the product. Measures like planning the tasks properly, using the software for monitoring and tracking the information, analysis related to time, and cost are performed, developing the system in the organization, etc.

\section{FACTOR GROUPING}

Factor grouping was done according to the Varimax rotation and nine-factor solution with eigenvalues $>1.000$, explaining $75.106 \%$ of the variance was formed, as shown in Table 1.It was noticed that the analysis resulted in nine groups for 33 factors and they are interpreted as follows.

\section{Factor grouping - 1 (Administration)}

Most factors in this group are managed by the administration department on the site where they look after, legal issues, land acquisition, and traffic plans. If the person having high experience and qualifications are involved, then it becomes easier for them to make decisions and it would result in less number of disputes among the project parties. But, in 
case of contractors and sub-contractors, the experience of the similar work smoothens the work on projects. Also, there are cases where they have experience and the can add value to the projects yet they being selfish and egoist they add value addition to their organizations only. It also poses risk of quality compromise. Many times, these factors become the reason for the project delay, which ultimately hasnegative impact on the value of the project.

Table 1 Total variance table from factor analysis

\begin{tabular}{c|ccc|ccc}
\hline \multirow{2}{*}{ Component } & \multicolumn{3}{|c|}{ Initial Eigen Values } & \multicolumn{3}{c}{ Rotation Sums of Squared Loadings } \\
\cline { 2 - 7 } & Total & $\begin{array}{c}\text { \% of } \\
\text { Variance }\end{array}$ & Cumulative \% & Total & $\begin{array}{c}\text { \% of } \\
\text { Variance }\end{array}$ & Cumulative \% \\
\hline 1 & 11.516 & 34.896 & 34.896 & 4.067 & 12.323 & 12.323 \\
2 & 2.876 & 8.714 & 43.610 & 3.579 & 10.846 & 23.169 \\
3 & 2.008 & 6.084 & 49.694 & 3.503 & 10.615 & 33.784 \\
4 & 1.823 & 5.523 & 55.216 & 2.949 & 8.935 & 42.719 \\
5 & 1.602 & 4.854 & 60.070 & 2.808 & 8.511 & 51.230 \\
6 & 1.432 & 4.340 & 64.410 & 2.705 & 8.197 & 59.427 \\
7 & 1.383 & 4.192 & 68.602 & 1.878 & 5.690 & 65.117 \\
8 & 1.124 & 3.407 & 72.009 & 1.656 & 5.017 & 70.134 \\
9 & 1.022 & 3.097 & 75.106 & 1.641 & 4.972 & 75.106 \\
10 & 0.918 & 2.781 & 77.887 & & & \\
11 & 0.835 & 2.531 & 80.418 & & & \\
12 & 0.775 & 2.347 & 82.765 & & & \\
13 & 0.711 & 2.155 & 84.920 & & & \\
14 & 0.599 & 1.816 & 86.737 & & & \\
15 & 0.509 & 1.542 & 88.278 & & & \\
\hline
\end{tabular}

\section{Factor grouping - 2 (Work environment)}

In a project, work environment plays a significant role. The less number of interference by the neighborhood, location feasibility, temperature, the space to store the material on site and availability of the design team on site for small clarity and corrections, attitude of the works and the staff, surrounding projects, what procurement strategies are followed for the project, etc. are key areas on which the site environment depends. In many contracting firms, some competitions and celebrations are there for a healthy environment on the site.

\section{Factor grouping - 3 (Culture)}

Culture must be developed on site, such that attitude of the individual at managerial level and the workers are good, staff members are taught leadership qualities, attitude for the organization and industry in individual, ethics, and morals followed by the organization, etc. Focusing on these areas unites the individuals working for the project and creates a good rapport on the site.

\section{Factor grouping -4 (Human resource)}

All the project participants should be well coordinated where the communication is very clear and the care for the requirements of the project participants should be taken. Along with this, the training programs and workshops for developing site management skills are 
required. Experienced leaders can provide motivation to the youth working with them and the atmosphere on the project remains healthy.

\section{Factor grouping - 5 (Compliance)}

For the compliance, planning must be a strong and quick response to the activities, such that while execution no difficulties are faced. Subsequently, the planned schedule should be followed without delays and without exceeding buffer time of the activities. During such scenario, the role of project coordinators is very important.

\section{Factor grouping - 6 (Management)}

Many times due to the client requirements, variation occurs in the on-going project which needs to be handled carefully. To adopt the changes quickly by accepting the new technologies and systems for the progress of the project - meetings and workshops are arranged, individuals are made aware of the new technologies, safety is taken care of, the status of the projects is evaluated, and difficulties are solved. Resource planning is carried out in advance considering geographical locations. Continuous evaluation of the project is carried out with the planned vs. actual data.

Factor grouping - 7 (Planning)

Precise planning is must to decide the priority. Execution must follow critical path. Constant tracking of the progress is required. Other than planning, distributing the information related to the short-term goalson the site is important. Planning influences the site management.

Table 2 Rotated Component Matrix for Factor Analysis

\begin{tabular}{|c|c|c|c|c|c|c|c|c|c|c|}
\hline \multirow{2}{*}{ Factors } & \multirow{2}{*}{ Citation } & \multicolumn{9}{|c|}{ Component } \\
\hline & & 1 & 2 & 3 & 4 & 5 & 6 & 7 & 8 & 9 \\
\hline Strong cost control systems* & 1 & 0.764 & & & & & & & & \\
\hline $\begin{array}{l}\text { Fast claim and payment } \\
\text { approval* }\end{array}$ & 1 & 0.737 & & & & & & & & \\
\hline $\begin{array}{l}\text { Personals with experience and } \\
\text { qualification* }\end{array}$ & 1 & 0.723 & & & & & & & & \\
\hline $\begin{array}{l}\text { Contractor's experience and } \\
\text { capability }\end{array}$ & & 0.619 & & & & & & & & \\
\hline Frequency of disputes* & 1 & 0.579 & & & & & & & & 0.512 \\
\hline $\begin{array}{l}\text { Quality of equipment's and } \\
\text { raw materials* }\end{array}$ & 1 & 0.542 & & & & & & & & \\
\hline $\begin{array}{l}\text { Level of neighborhood/public } \\
\text { interest* }\end{array}$ & 3 & & 0.769 & & & & & & & \\
\hline Local construction market* & 3 & & 0.690 & & & & & & & \\
\hline Material Handling \& Storage & & & 0.689 & & & & & & & \\
\hline $\begin{array}{l}\text { Availability of design team on } \\
\text { site }\end{array}$ & & & 0.623 & & & & & & & \\
\hline $\begin{array}{l}\text { Delivery or procurement } \\
\text { approach* }\end{array}$ & 2 & & 0.600 & & & & & & & \\
\hline Recycling and reuse of waste* & 4 & & & 0.778 & & & & & & \\
\hline
\end{tabular}




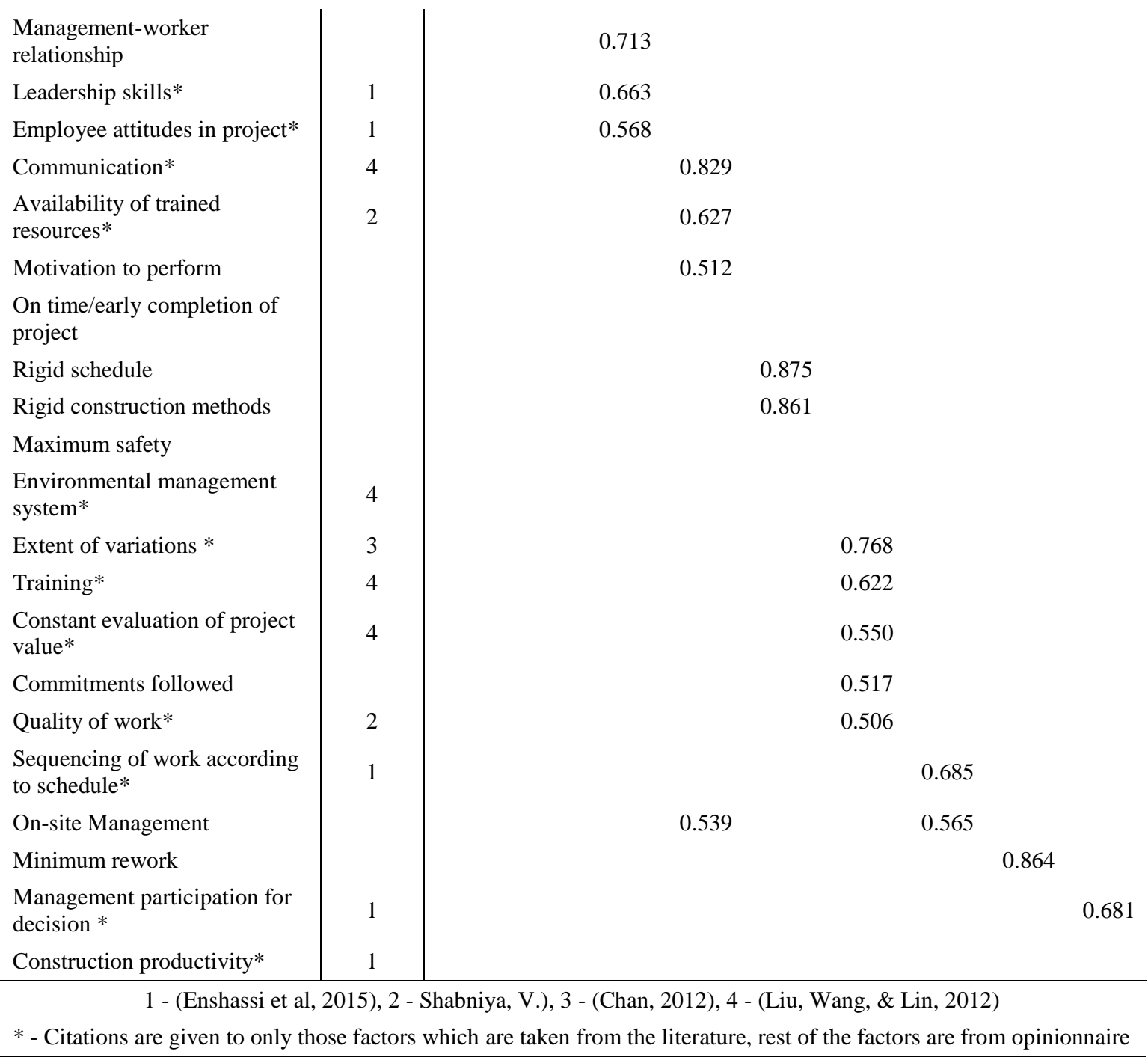

\section{Factor grouping - 8 (Rework)}

If any tasks are required to perform again, the amount of resources used will increase which results in more time and cost. Visual tools can help understand tasks easily which would account in less amount of rework and wastage.

\section{Factor grouping - 9 (Transparency)}

If people in different levels in hierarchy are involved in the decision making, then the information will be shared with all the participants in the hierarchywhich helps to maintain the transparency. These would result, in less number of disputes internally in the organization and it would smoothen the work throughout the project for all the project participants. 


\section{APPLICABILITY AND EASE OF IMPLEMENTATION MATRIX}

\section{Applicability Matrix}

Table 3 Applicability Matrix

\begin{tabular}{|c|c|c|c|c|c|c|c|c|c|c|c|c|c|c|c|}
\hline \multirow{2}{*}{ FACTORS } & \multicolumn{12}{|c|}{ TOOLS } & \multicolumn{3}{|c|}{ SCORE } \\
\hline & 1 & 2 & 3 & 4 & 5 & 6 & 7 & 8 & 9 & 10 & 11 & 12 & $\begin{array}{c}\text { Obtai } \\
\text { ned }\end{array}$ & Max. & $\%$ \\
\hline Commitments followed & 5 & 4 & 4 & 6 & 6 & 6 & 4 & 1 & 6 & 4 & 4 & 4 & 53 & 120 & 44 \\
\hline Communication & 5 & 4 & 4 & 4 & 9 & 6 & 7 & 4 & 4 & 4 & 7 & 5 & 63 & 120 & 52 \\
\hline Leadership skills & 4 & 2 & 3 & 2 & 3 & 5 & 2 & 3 & 2 & 3 & 3 & 3 & 34 & 120 & 28 \\
\hline Minimum rework & 7 & 4 & 4 & 5 & 8 & 6 & 7 & 4 & 4 & 5 & 3 & 8 & 64 & 120 & 54 \\
\hline Motivation to perform & 8 & 3 & 2 & 3 & 6 & 6 & 3 & 3 & 2 & 4 & 3 & 3 & 46 & 120 & 38 \\
\hline On time/early completion of project & 6 & 5 & 6 & 6 & 6 & 8 & 5 & 4 & 6 & 7 & 5 & 7 & 70 & 120 & 58 \\
\hline On-site Management & 6 & 7 & 5 & 7 & 9 & 6 & 7 & 3 & 3 & 6 & 7 & 5 & 69 & 120 & 58 \\
\hline Participation of management & 3 & 5 & 4 & 4 & 5 & 5 & 3 & 4 & 2 & 4 & 4 & 4 & 46 & 120 & 39 \\
\hline Employee attitudes in project & 7 & 4 & 3 & 2 & 7 & 6 & 3 & 3 & 3 & 5 & 5 & 5 & 51 & 120 & 43 \\
\hline Delivery or procurement approach & 3 & 5 & 3 & 6 & 4 & 8 & 5 & 3 & 4 & 8 & 4 & 4 & 57 & 120 & 48 \\
\hline Fast claim and payment approval & 4 & 4 & 3 & 3 & 3 & 8 & 4 & 3 & 4 & 4 & 3 & 3 & 43 & 120 & 36 \\
\hline Stipulated schedule & 5 & 5 & 5 & 4 & 4 & 5 & 4 & 4 & 5 & 7 & 5 & 4 & 56 & 120 & 46 \\
\hline Construction productivity & 8 & 7 & 8 & 6 & 5 & 8 & 6 & 7 & 8 & 7 & 6 & 7 & 84 & 120 & 70 \\
\hline Material Handling \& Storage & 8 & 3 & 3 & 3 & 5 & 5 & 7 & 4 & 4 & 5 & 3 & 4 & 54 & 120 & 45 \\
\hline $\begin{array}{l}\text { Quality of equipment's and raw } \\
\text { materials }\end{array}$ & 5 & 3 & 3 & 2 & 3 & 3 & 4 & 4 & 3 & 4 & 4 & 6 & 43 & 120 & 36 \\
\hline Quality of work & 4 & 4 & 5 & 5 & 4 & 4 & 3 & 5 & 5 & 3 & 4 & 7 & 53 & 120 & 44 \\
\hline Contractor's experience and capability & 3 & 4 & 3 & 3 & 3 & 4 & 3 & 3 & 3 & 3 & 4 & 6 & 42 & 120 & 35 \\
\hline Extent of variations & 4 & 5 & 8 & 6 & 6 & 6 & 7 & 8 & 4 & 6 & 4 & 8 & 71 & 120 & 59 \\
\hline Strong cost control systems & 6 & 5 & 4 & 6 & 4 & 4 & 4 & 4 & 4 & 4 & 4 & 4 & 50 & 120 & 42 \\
\hline Constant evaluation of project & 4 & 3 & 5 & 7 & 3 & 6 & 4 & 4 & 3 & 3 & 5 & 3 & 50 & 120 & 42 \\
\hline Frequency of disputes & 5 & 4 & 5 & 7 & 5 & 7 & 6 & 4 & 5 & 4 & 4 & 4 & 60 & 120 & 50 \\
\hline Level of public interest & 3 & 3 & 3 & 3 & 3 & 2 & 2 & 3 & 2 & 2 & 3 & 3 & 30 & 120 & 25 \\
\hline Management-worker relationship & 6 & 4 & 3 & 4 & 4 & 6 & 4 & 4 & 4 & 4 & 7 & 3 & 50 & 120 & 42 \\
\hline Environmental management & 4 & 2 & 3 & 4 & 5 & 3 & 4 & 3 & 3 & 2 & 3 & 5 & 39 & 120 & 33 \\
\hline Recycling and reuse of waste & 4 & 3 & 3 & 3 & 3 & 4 & 4 & 3 & 4 & 4 & 3 & 6 & 42 & 120 & 35 \\
\hline Local construction market & 3 & 3 & 3 & 3 & 4 & 6 & 4 & 4 & 4 & 3 & 4 & 3 & 42 & 120 & 35 \\
\hline Availability of design team on site & 3 & 4 & 5 & 5 & 3 & 4 & 4 & 5 & 4 & 3 & 4 & 4 & 47 & 120 & 39 \\
\hline $\begin{array}{l}\text { Personals with experience and } \\
\text { qualification }\end{array}$ & 4 & 4 & 4 & 5 & 3 & 4 & 3 & 5 & 4 & 3 & 4 & 5 & 45 & 120 & 38 \\
\hline Availability of trained resources & 3 & 4 & 4 & 5 & 3 & 5 & 3 & 4 & 3 & 4 & 5 & 4 & 46 & 120 & 38 \\
\hline Maximum safety & 8 & 5 & 5 & 5 & 8 & 3 & 6 & 4 & 3 & 3 & 4 & 6 & 59 & 120 & 49 \\
\hline Trainings & 4 & 3 & 6 & 5 & 5 & 3 & 3 & 3 & 4 & 3 & 7 & 4 & 49 & 120 & 41 \\
\hline Obtained score & 149 & 121 & 125 & 136 & 145 & 160 & 132 & 117 & 117 & 129 & 133 & 145 & & & \\
\hline Max. Score & 310 & 310 & 310 & 310 & 310 & 310 & 310 & 310 & 310 & 310 & 310 & 310 & & & \\
\hline$\%$ & 48 & 39 & 40 & 44 & 47 & 52 & 43 & 38 & 38 & 42 & 43 & 47 & & & \\
\hline
\end{tabular}

Tools Coding - (1-5S, 2-Andon, 3-Augmented Construction Field Visualization, 4 -BIM, 5-Display Boards, 6-Collobrative Process Mapping /LPS, 7Color Coding, 8-End Product Samples, 9-Heijunka, 10-Kanban Cards, 11-Obeya Rooms, 12- Poka-Yoke)

Red Colour depicts - minimum applicability of the tool to the factor

Blue Colour depicts - maximum applicability of the tool to the factor

Table 3 shows the matrix comprising of factors and the tools, which represents how relevant is the visual tool, to the identified factors during the construction phase. These factors are relatively graded out of 10 , to find out the most useful tools for improving the factors. (Where 0-not applicable, 1-least relevant and 10-most relevant).

When the matrix is read vertically, tool scores highlighted in green colour at bottom of the matrix would be helpful if only one or two tools are being adopted on the site and it has its effect on all the factors according to the obtained score. Here the top five tools which can be used on the site are 5S, BIM, Display boards, Collaborative Process Mapping / LPS, Poke-Yoke.

Whereas if the particular factors are required to be improved on site, than those factors having maximum score in the right side of the matrix, highlighted in green colour can be achieved by all the tools listed in the matrix. The top 10 factors among the 
identified factors which can be improved with the listed tools are communication, minimum rework, on time/early completion of project, on-site management, delivery or procurement approach, stipulated schedule, construction productivity, extent of variations, frequency of disputes and maximum safety.

\section{Ease of implementation Matrix}

Table 4 Ease of implementation Matrix

\begin{tabular}{|c|c|c|c|c|c|c|c|c|c|c|c|c|c|c|c|}
\hline \multirow[b]{2}{*}{ FACTORS } & \multicolumn{12}{|c|}{ TOOLS } & \multicolumn{3}{|c|}{ SCORE } \\
\hline & 1 & 2 & 3 & 4 & 5 & 6 & 7 & 8 & 9 & 10 & 11 & 12 & $\begin{array}{l}\text { Obta } \\
\text { ined }\end{array}$ & Max. & $\%$ \\
\hline Commitments followed & 3 & 4 & 5 & 7 & 5 & 5 & 5 & 4 & 5 & 4 & 4 & 3 & 52 & 120 & 43 \\
\hline Communication & 3 & 4 & 5 & 5 & 5 & 5 & 6 & 5 & 4 & 4 & 6 & 4 & 55 & 120 & 46 \\
\hline Leadership skills & 4 & 3 & 3 & 4 & 4 & 5 & 4 & 4 & 3 & 3 & 3 & 3 & 40 & 120 & 34 \\
\hline Minimum rework & 5 & 5 & 5 & 6 & 6 & 5 & 5 & 5 & 4 & 5 & 4 & 7 & 61 & 120 & 51 \\
\hline Motivation to perform & 5 & 4 & 4 & 4 & 6 & 5 & 4 & 4 & 3 & 4 & 4 & 3 & 49 & 120 & 41 \\
\hline $\begin{array}{l}\text { On time/early completion of } \\
\text { project }\end{array}$ & 5 & 5 & 7 & 6 & 5 & 7 & 5 & 5 & 6 & 5 & 6 & 6 & 68 & 120 & 57 \\
\hline On-site Management & 5 & 5 & 5 & 7 & 7 & 5 & 7 & 4 & 4 & 6 & 6 & 4 & 64 & 120 & 53 \\
\hline Participation of management & 3 & 5 & 4 & 5 & 5 & 5 & 4 & 5 & 4 & 4 & 5 & 4 & 51 & 120 & 42 \\
\hline Employee attitudes in project & 5 & 4 & 4 & 4 & 7 & 5 & 5 & 5 & 4 & 3 & 4 & 4 & 53 & 120 & 44 \\
\hline Delivery or procurement approach & 3 & 4 & 3 & 6 & 4 & 6 & 4 & 4 & 4 & 4 & 4 & 4 & 49 & 120 & 41 \\
\hline Fast claim and payment approval & 4 & 3 & 4 & 4 & 4 & 6 & 3 & 4 & 3 & 3 & 4 & 4 & 44 & 120 & 36 \\
\hline Stipulated schedule & 4 & 4 & 5 & 5 & 5 & 5 & 4 & 5 & 4 & 5 & 5 & 4 & 54 & 120 & 45 \\
\hline Construction productivity & 6 & 6 & 8 & 7 & 6 & 7 & 5 & 7 & 7 & 5 & 5 & 6 & 72 & 120 & 60 \\
\hline Material Handling \& Storage & 6 & 3 & 3 & 4 & 6 & 4 & 6 & 4 & 3 & 4 & 3 & 3 & 49 & 120 & 41 \\
\hline $\begin{array}{l}\text { Quality of equipment's and raw } \\
\text { materials }\end{array}$ & 5 & 3 & 3 & 3 & 5 & 4 & 4 & 5 & 3 & 3 & 3 & 5 & 42 & 120 & 35 \\
\hline Quality of work & 4 & 4 & 4 & 6 & 6 & 4 & 4 & 5 & 5 & 3 & 3 & 4 & 51 & 120 & 42 \\
\hline $\begin{array}{l}\text { Contractor's experience and } \\
\text { capability }\end{array}$ & 3 & 4 & 3 & 4 & 5 & 4 & 4 & 4 & 4 & 3 & 3 & 5 & 45 & 120 & 37 \\
\hline Extent of variations & 4 & 4 & 8 & 7 & 6 & 5 & 5 & 7 & 4 & 4 & 4 & 6 & 63 & 120 & 52 \\
\hline Strong cost control systems & 5 & 5 & 3 & 6 & 4 & 4 & 4 & 5 & 3 & 3 & 4 & 4 & 50 & 120 & 41 \\
\hline Constant evaluation of project & 2 & 2 & 3 & 6 & 2 & 4 & 2 & 2 & 3 & 2 & 4 & 3 & 33 & 120 & 28 \\
\hline Frequency of disputes & 4 & 4 & 4 & 6 & 5 & 7 & 4 & 4 & 4 & 3 & 3 & 4 & 51 & 120 & 43 \\
\hline Level of public interest & 3 & 3 & 3 & 3 & 3 & 4 & 3 & 4 & 2 & 2 & 2 & 2 & 34 & 120 & 28 \\
\hline Management-worker relationship & 5 & 5 & 3 & 3 & 4 & 6 & 4 & 3 & 3 & 3 & 5 & 3 & 46 & 120 & 38 \\
\hline Environmental management & 4 & 3 & 3 & 4 & 5 & 4 & 4 & 4 & 3 & 3 & 3 & 6 & 44 & 120 & 37 \\
\hline Recycling and reuse of waste & 4 & 3 & 3 & 3 & 4 & 4 & 3 & 4 & 2 & 3 & 4 & 6 & 42 & 120 & 35 \\
\hline Local construction market & 3 & 3 & 3 & 3 & 3 & 5 & 3 & 4 & 3 & 2 & 3 & 3 & 36 & 120 & 30 \\
\hline Availability of design team on site & 3 & 3 & 4 & 4 & 3 & 4 & 4 & 5 & 3 & 3 & 4 & 3 & 40 & 120 & 33 \\
\hline $\begin{array}{l}\text { Personals with experience and } \\
\text { qualification }\end{array}$ & 3 & 3 & 3 & 4 & 3 & 5 & 4 & 5 & 2 & 3 & 4 & 3 & 39 & 120 & 33 \\
\hline Availability of trained resources & 2 & 3 & 3 & 4 & 4 & 5 & 4 & 4 & 2 & 3 & 4 & 3 & 41 & 120 & 34 \\
\hline Maximum safety & 5 & 4 & 4 & 4 & 5 & 4 & 5 & 4 & 2 & 3 & 4 & 5 & 48 & 120 & 40 \\
\hline Trainings & 2 & 3 & 6 & 5 & 4 & 3 & 3 & 6 & 3 & 3 & 5 & 3 & 45 & 120 & 37 \\
\hline Obtained score & 119 & 111 & 125 & 148 & 143 & 148 & 130 & 136 & 106 & 105 & 120 & 121 & & & \\
\hline Max. Score & 310 & 310 & 310 & 310 & 310 & 310 & 310 & 310 & 310 & 310 & 310 & 310 & & & \\
\hline$\%$ & 38 & 36 & 40 & 48 & 46 & 48 & 42 & 44 & 34 & 34 & 39 & 39 & & & \\
\hline
\end{tabular}

Table 4 shows the matrix of factors and tools, which represents how easy the tools are for the factors to implement on the site during the construction phase. These factors are relatively graded out of 10 , that which is the most useful tools for improving the factors. (0-not applicable, 1-difficult to implement and 10-easy to implement).

When the matrix is read vertically, tool scores highlighted in green colour at bottom of the matrix would be helpful if only one or two tools are being adopted on the site, and it has its effect on all the factors according to the obtained score. Here the top five tools 
which can be used on the site are BIM, display boards, collaborative process mapping / LPS, colour coding, end sample products.

Whereas if the particular factors are required to be improved on site, than those factors having maximum score in the right side of the matrix, highlighted in green colour can be achieved by all the tools listed in the matrix. The top 10 factors among the identified factors which can be improved are Commitments followed, communication, minimum rework, on time/early completion of project, on-site management, Employee attitudes in project, stipulated schedule, construction productivity, extent of variations, frequency of disputes and maximum safety.

\section{CONCLUSION}

In India, construction industry professional believes that equal efforts in process and product both for the value enhancement. Authorities responsible for improving the project value in sequence are: client, consultant, and contractor. The value in the construction industry revolves around cost, time, and quality. Maximum emphasis is given to cost. Safety and environment are also considered vital.

Total 33 factors are identified that can increase the value of the project and they are distributed into nine groups using factor analysis as: administration, work environment, culture, human resource, compliance, management, planning, rework, and transparency.

Visual tools can be used on the construction projects and they can help to improve the value. Most relevant tools to enhance the value of construction project include 5S, display boards, collaborative process mapping /LPS, Kanban cards, Obeya rooms, Poke-yoke. Whereas BIM, display boards, collaborative process mapping / LPS, colour coding, end product samples are easy to implement on-site for improving the value.

\section{REFERENCES}

Anerao, S. D., \& Deshmukh, S. S. (2016). Waste minimization by lean construction technology. IRJET, 3(8), 1703-1707.

Chan, C. T. W. (2012). The principal factors affecting construction project overhead expenses: An exploratory factor analysis approach. Construction Management and Economics, 30(10), 903-914. https://doi.org/10.1080/01446193.2012.717706

Enshassi, A., Mohamed, S., \& Abushaban, S. (2015). Factors affecting the performance of construction projects in the Gaza strip, 3730(November), 1-43. https://doi.org/10.3846/1392-3730.2009.15.269-280

Johnson, J. W., \& LeBreton, J. M. (2004). History and use of relative importance indices in organizational research. Organizational Research Methods, 7(3), 238-257.

Kashiwagi, D., \& Savicky, J. (2003). The cost of 'best value construction. Journal of Facilities Management, 2(3), 285-297.

Kelly, J., Male, S., \& Graham, D. (2004). Value Management of Construction Project.

Kelly, J., Morledge, R., \& Wilkinson, S. J. (Eds.) (2009). Best value in construction. JW\&S.

Koskela, L.; Howell, G.; Ballard, G.; Tommelein, I. (2002). "Foundations of Lean Construction". In Best, Rick; de Valence, Gerard. Design and Construction: Building in Value. Oxford, UK: Butterworth-Heinemann, Elsevier. ISBN 0750651490. 
Liu, J. K., Wang, Y. S., \& Lin, Y. Y. (2012). Critical Success Factors for Construction and Demolition Waste Management in Pearl River Delta of China. Applied Mechanics and Materials, 174-177, 3245-3252. https://doi.org/10.4028/www.scientific.net/AMM.174-177.3245

Morgan, D. W., \& Krejcie, R. V. (1970). Determining Sample Size for Research Activities. Educational and Psychological Measurement, 30, 607-610.

Norusis, M.J. (1992) SPSS for Windows, Professional Statistics, SPSS Inc., Chicago.

Parry, G. C., \& Turner, C. E. (2006). Application of lean visual process management tools. Production planning \& control, 17(1), 77-86.

Saunders, M., Lewis, P., \& Thornhill, A. (2007). Research Methods for Business Students, (6th ed.) London: Pearson.

Shabniya, V. (2017). Factors Affecting Construction Cost Estimation of Building Projects. International Journal of Recent Trends in Engineering and Research, 3 (4), 379-387.

Spector, J. M., Merrill, M. D., Elen, J., \& Bishop, M. J. (Eds.). (2014). Handbook of research on educational communications and technology (pp. 439-451). NY: Springer.

Tezel, A. (2011). Visual management: an exploration of the concept and its implementation in construction (Ph.D. Thesis). University of Salford, UK.

Tezel, B. A., Koskela, L. J., \& Tzortzopoulos Fazenda, P. (2013). Visual management in industrial construction: a case study.

Tezel, A., Aziz, Z., Koskela, L., \& Tzortzopoulos, P. (2016). Benefits of visual management in the transportation sector.

Tezel, A., \& Aziz, Z. (2017). Benefits of visual management in construction: cases from the transportation sector in England. Construction Innovation, 17(2), 125-157.

The Association for Educational Communications and Technology. (2018). What Is Descriptive Research?.

Tobergte, D. R., \& Curtis, S. (2013). Social research methods. Journal of Chemical Information and Modeling, 53(9), 1689-1699.

Trochim, W., \& Donnelly, J. (2006). The research knowledge methods base. Cincinnati, OH: Atomic Dog Publishing. 